\title{
Structural and chemical determination of the new nanolaminated carbide Mo2Ga2C from first principles and materials analysis
}

Chung-Chuan Lai, Rahele Meshkian, Martin Dahlqvist, Jun Lu, Lars-Åke Näslund, O. Rivin,

E. N. Caspi, O. Ozeri, Lars Hultman, Per Eklund, Michel Barsoum and Johanna Rosén

\section{Linköping University Post Print}

\section{Tweet}

N.B.: When citing this work, cite the original article.

Original Publication:

Chung-Chuan Lai, Rahele Meshkian, Martin Dahlqvist, Jun Lu, Lars-Åke Näslund, O. Rivin, E. N. Caspi, O. Ozeri, Lars Hultman, Per Eklund, Michel Barsoum and Johanna Rosén, Structural and chemical determination of the new nanolaminated carbide Mo2Ga2C from first principles and materials analysis, 2015, Acta Materialia, (99), 157-164.

http://dx.doi.org/10.1016/j.actamat.2015.07.063

Copyright: Elsevier

http://www.elsevier.com/

Postprint available at: Linköping University Electronic Press

http://urn.kb.se/resolve?urn=urn:nbn:se:liu:diva-122193 


\section{Structural and chemical determination of the new nanolaminated carbide $\mathrm{Mo}_{2} \mathrm{Ga}_{2} \mathrm{C}$ from first principles and materials analysis}

C.-C. Lai ${ }^{\text {a }}$, R. Meshkian ${ }^{\text {a }}$, M. Dahlqvist ${ }^{\text {a }}$, J. Lu ${ }^{\text {a }}$, L.-Å. Näslund ${ }^{\text {a }}$, O. Rivin ${ }^{\text {b }}$, E.N. Caspi ${ }^{\text {b }}$, O. Ozeri $^{\text {c }}$, L. Hultman a ${ }^{\text {a }}$ P. Eklund ${ }^{\text {a }}$, M.W. Barsoum ${ }^{\text {a,d,* }}$, J. Rosen ${ }^{\text {a,* }}$

${ }^{a}$ Thin Film Physics Division, Department of Physics, Chemistry, and Biology (IFM), Linköping University, Linköping SE-58183, Sweden

b Physics Department, Nuclear Research Centre-Negev, P.O. Box 9001, Beer-Sheva 84190, Israel

${ }^{\mathrm{c}}$ Reactor Department, Nuclear Research Center-Soreq, Yavne 81800, Israel

d Department of Materials Science and Engineering, Drexel University, PA 19104, United States

* Corresponding authors at: Department of Materials Science and Engineering, Drexel University, PA 19104, United States (M.W. Barsoum), and Thin Film Physics Division, Department of Physics, Chemistry, and Biology (IFM), Linköping University, Linköping SE58183, Sweden (J. Rosen). E-mail addresses: barsoumw@drexel.edu (M.W. Barsoum), johro@ifm.liu.se (J. Rosen). 


\begin{abstract}
Following our recent discovery of a new nanolaminated carbide, $\mathrm{Mo}_{2} \mathrm{Ga}_{2} \mathrm{C}$, we herein present a detailed structural and chemical analysis of this phase based on ab initio calculations, X-ray photoelectron spectroscopy, high resolution scanning transmission electron microscopy, and neutron powder diffraction. Calculations suggest an energetically and dynamically stable structure for $\mathrm{C}$ in the octahedral sites between the Mo layers, with Ga bilayers - stacked in a simple hexagonal arrangement - between the $\mathrm{Mo}_{2} \mathrm{C}$ layers. The predicted elastic properties are below those of the related nanolaminate $\mathrm{Mo}_{2} \mathrm{GaC}$. The predicted structure, including lattice parameters and atomic positions, is experimentally confirmed.
\end{abstract}

\title{
1. Introduction
}

The $M_{n+1} A X_{n}$ (MAX) phases, with $n=1-3$, are inherently nanolaminated materials, where $M$ is an early transition metal, $A$ is an A-group element (mainly group 13 or 14), and $X$ is $\mathrm{C}$ or $\mathrm{N}$ [14]. Structurally, the MAX phases can be described as $M_{n+1} X_{n}$ layers interleaved by monolayers of pure $A$ element, for which two adjacent $M_{n+1} X_{n}$ layers are twinned across it. So far, more than 70 MAX phases have been synthesized. Before the late 2000s most predictions were carried out in an ad hoc fashion due to a lack of a comprehensive understanding of the respective material systems [5-8]. It is not until the last few years that the theoretical methods have been more systematic, which in turn provides better guidance for experimentalists to look for new MAX phases, see e.g. references [9-12].

Recently, we reported on a new ternary carbide, $\mathrm{Mo}_{2} \mathrm{Ga}_{2} \mathrm{C}$, both in thin film and bulk form [13]. Similar to its MAX phase counterpart, $\mathrm{Mo}_{2} \mathrm{GaC}, \mathrm{Mo}_{2} \mathrm{Ga}_{2} \mathrm{C}$ is laminated, but instead of $\mathrm{Ga}$ monolayers interleaving the $\mathrm{Mo}_{2} \mathrm{C}$ blocks, there is a $\mathrm{Ga}$ double-layer (bilayer) between the carbide layers. The resulting phase is of great interest because of its structural similarity with 
$\mathrm{Mo}_{2} \mathrm{GaC}$, which is the only Mo-containing MAX phase synthesized so far. Other conceivable MAX phases within the Mo-Ga-C system are predicted to be not stable, i.e. positive formation enthalpy, with respect to their competing phases [14].

In our previous report, structural and compositional analysis of $\mathrm{Mo}_{2} \mathrm{Ga}_{2} \mathrm{C}$ was performed by $\mathrm{X}$ ray diffraction (XRD), transmission electron microscopy (TEM), and elastic recoil detection analysis (ERDA). However, even though we argued that the most plausible position of $\mathrm{C}$ in the structure was in the octahedral sites between the Mo layers, direct evidence was lacking. Quite surprisingly, the Ga layers were stacked in a simple hexagonal arrangement, one that is quite rare in metals.

The purpose of this work is to explore the structure and chemistry of $\mathrm{Mo}_{2} \mathrm{Ga}_{2} \mathrm{C}$. We have therefore investigated the phase stability of $\mathrm{Mo}_{2} \mathrm{Ga}_{2} \mathrm{C}$ from first principles, with respect to possible competing phases in the Mo-Ga-C system, and in different structural and chemical order. We also calculated its elastic constants and electronic structure. Thermal neutron powder diffraction (NPD) was used to supplement the experimental investigation due to the sensitivity to $\mathrm{C}$ and $\mathrm{Ga}$ positions within the unit cell, in the presence of Mo atoms. Based on our theoretical modeling, combined with X-ray photoelectron spectra (XPS) and NPD, we have definitively determined the structure of this compound.

\section{Computational details}

First-principles calculations were carried out using the projector augmented wave (PAW) method [15] as implemented within the Vienna ab initio simulation package (VASP) [16-18]. We adopted the generalized gradient approximation (GGA) as parameterized by PerdewBurke-Ernzerhof (PBE) [19] for treating electron exchange and correlation effects. Wave functions are expanded in a plane-wave basis set with an energy cutoff of $400 \mathrm{eV}$ and for 
sampling of the Brillouin zone we used the Monkhorst-Pack scheme [20]. The calculated total energy for all phases is converged to within $0.1 \mathrm{meV} /$ atom in terms of $k$-point sampling. Structural optimizations were performed in terms of unit-cell volumes, cla ratios (when necessary), and internal parameters to minimize the total energy.

\section{Experimental details}

$\mathrm{Mo}_{2} \mathrm{Ga}_{2} \mathrm{C}$ thin films were deposited by direct current magnetron sputtering (DCMS) with 3 elemental targets: Mo $(\varnothing \approx 7.6 \mathrm{~cm}, 99.95 \%$ purity, SCOTECH Ltd. $), \mathrm{Ga}(\varnothing \approx 5.1 \mathrm{~cm}$, 99.99999\% purity, 5N Plus UK Ltd.) and C ( $\approx \approx 7.6 \mathrm{~cm}, 99.99 \%$ purity, SCOTECH Ltd.), in $\sim 0.5 \mathrm{~Pa}$ Ar with a base pressure in the range of $10^{-7} \mathrm{~Pa}$. The Ga target was placed in a horizontal position, facing upwards, along the substrate normal, while the Mo and $\mathrm{C}$ targets were tilted $35^{\circ}$ away from the substrate normal, co-focused on the substrate. Details about sputtering from a liquid Ga target as well as the deposition system are described elsewhere [21]. The $\mathrm{MgO}(111)$ substrates were cleaned sequentially in acetone, ethanol and isopropanol ultrasonic bath for 10 min each. During depositions, the substrates were kept at $560{ }^{\circ} \mathrm{C}$ and rotated at $30 \mathrm{rpm}$ in order to obtain more chemically homogeneous films.

The NPD experiment was carried out at the KARL double-axis diffractometer, mounted on the Israeli Research Reactor No. 1 (IRR-1) at the Nuclear Research Center, Soreq, Israel (Israel's Atomic Energy Commission) [22]. The measurement was carried out at room temperature, with an incident neutron wavelength of $0.982(1) \AA$. This low incident wavelength, combined with an angular step of $0.05^{\circ}$ and a $\sim 0.25^{\circ}$ monochromating single crystal's mosaicity, generated sufficient angular range and angular resolution for this crystallographic study. The preparation of $\mathrm{Mo}_{2} \mathrm{Ga}_{2} \mathrm{C}$ powder samples for the NPD experiment is described in our previous work [13]. A $~ 10$ g powder sample was loaded into a vanadium cylindrical sample holder, which was used 
to significantly reduce coherent scattering from the holder. The results obtained were analyzed using the Rietveld refinement method, applied using the FullProf software package [23].

To acquire cross-sectional images and compositional maps on thin film samples, high resolution scanning transmission electron microscopy (HR-STEM) and X-ray energy dispersive spectroscopy (EDX) were performed within the Linköping double $\mathrm{C}_{\mathrm{s}}$ corrected FEI Titan ${ }^{3} 60$ 300 microscope equipped with the Super-X EDX system and operated at $300 \mathrm{kV}$.

XPS on phase pure thin films was performed using an AXIS Ultra ${ }^{\text {DLD }}$ system from Kratos and monochromatic $\mathrm{Al} \mathrm{K}_{\alpha}$ radiation. To avoid charging, caused by electron depletion while recording the XPS spectra, the samples were exposed to an electron flood gun. The binding energy scale of all XPS spectra presented here was calibrated against the Fermi edge $\left(E_{f}\right)$, which was set to a binding energy of $0 \mathrm{eV}$. The overall energy resolution obtained was better than 0.5 $\mathrm{eV}$. Normalization of all spectra was performed at the background on the low binding energy side of the main peak/-peaks. Prior to the acquisition of the spectra, the samples were exposed

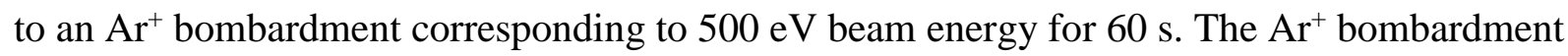
was performed at an angle of $25^{\circ}$ relative the surface, which efficiently removes most oxide overlayers and most of the carbon containing contamination.

\section{Results and discussion}

The position of carbon in the crystal structure of $\mathrm{Mo}_{2} \mathrm{Ga}_{2} \mathrm{C}$ is challenging to obtain from STEM. However, STEM images revealed a relatively large atomic spacing between two adjacent Mo layers and two adjacent Ga layers. The more likely location for the $\mathrm{C}$ atoms - and the one we assumed in our first report [13] - is the octahedral sites created by the Mo layers (Fig. 1(a)). Other possibilities include structures with $\mathrm{C}$ atoms in between the Ga layers (Fig. 1(b)) or with the $\mathrm{C}$ between the Mo layers, but in a 'zig-zag' arrangement of Ga layers (Fig. 1(c)). 
For a phase with a given composition and structure to be thermodynamically stable, its energy needs to be lower than the energy of any stoichiometric linear combination of all other competing phases in the system, that is

$$
\Delta H_{c p}=E\left(\mathrm{Mo}_{2} \mathrm{Ga}_{2} \mathrm{C}\right)-E(\text { competing phases })<0
$$

In order to identify the set of most competing phases at the $\mathrm{Mo}_{2} \mathrm{Ga}_{2} \mathrm{C}$ composition we make use of a linear optimization procedure $[24,25]$ which has proven successful in confirming already experimentally known MAX phases, as well as predicting the existence of new ones [25-27]. Table 1 lists all competing phases together with their respective calculated volume, lattice parameters, and total energies.

In Table 2, the calculated equilibrium energies and lattice parameters show that $\mathrm{Mo}_{2} \mathrm{Ga}_{2} \mathrm{C}$, with $\mathrm{C}$ atoms between the Mo-layers (Fig. 1(a)) is the most likely structure with a calculated negative $\Delta H_{c p}$ of $-9 \mathrm{meV} / \mathrm{atom}$. The energies for the structures with either $\mathrm{C}$ atoms between the $\mathrm{Ga}$ layers (Fig. 1(b)) or C atoms between the Mo layer plus a zigzag stacking of the Ga atoms (Fig. 1(c)), are significantly higher, +786 and $+124 \mathrm{meV} / \mathrm{atom}$, respectively. The latter two structures would also have $c$ parameters well below $18 \AA$, which is inconsistent with previous experimental results [13].

To further explore the various possible $\mathrm{Mo}_{2} \mathrm{Ga}_{2} \mathrm{C}$ structures we calculated their phonon spectra using the Phonopy code in combination with density functional perturbation theory in VASP using $4 \times 4 \times 1$ supercells. Fig. 2(a)-(c) shows the results for the structures shown in Fig. 1(a)(c), respectively, from which we can conclude that the structure shown in Fig. 1(a) is dynamically stable, i.e. stable relative to lattice vibrations as evidenced by the fact that no imaginary phonon frequencies exist in the phonon spectrum. When the $\mathrm{C}$ atoms are placed between the Ga-layers (Fig. 1(b)), the phonon spectrum (Fig. 2(b)) is negative along some 
directions, confirming that this structure is dynamically unstable. The same result applies for the zig-zag stacking of Ga (Figs. 1(c) and 2(c)).

In Table 3, the calculated $a$ and $c$ lattice parameters and the structural model of the most stable structure (Fig. 1(a)) are summarized, together with previous results from XRD Rietveld analysis [13]. The $\mathrm{Ga}$ and Mo atomic arrangements are thus consistent with our previous suggestion based on STEM images acquired along the [100] and [210] zone axes of the $\mathrm{Mo}_{2} \mathrm{Ga}_{2} \mathrm{C}$ phase as well as Rietveld analysis of the XRD patterns. Furthermore, the calculated $a$ and $c$ lattice parameters are in good agreement with the ones obtained from XRD. The Mo double-layers, with $\mathrm{C}$ atoms occupying the octahedral interstitial sites, is identical to that found for the $M-\mathrm{C}$ layers in other $M_{2} A X$ phases. In fact, the only structural difference between the $M_{2} A_{2} X$ and $M_{2} A X$ is the insertion of an extra $A$ layer. We conclude that in $\mathrm{Mo} 2 \mathrm{Ga} 2 \mathrm{C}$ the $\mathrm{C}$ atoms reside between the Mo layers and that the Ga atoms are stacked in a simple hexagonal arrangement (Fig. 1(a)).

The NPD results were analyzed assuming the $P 6_{3} / m m c$ space group, with the Mo and Ga atoms occupying the ' $4 \mathrm{f}$ ' site and the $\mathrm{C}$ atoms occupying the '2a' site (Fig. 1(a)). The $\mathrm{C}$ occupancy was assumed to be incomplete within the refinement process, $\mathrm{Mo}_{2} \mathrm{Ga}_{2} \mathrm{C}_{1-x}$, with $x$ representing the deviation from complete occupation of the ' $2 \mathrm{a}$ ' site. In addition to $x$, the refinement process yields the unit cell size parameters, the Mo and Ga layers position, $z \mathrm{Mo}$ and $z \mathrm{Ga}$, within the unit cell, respectively, and their mean-square displacement (assumed to be isotropic) from equilibrium position, $\left\langle\mathrm{u}^{2}\right\rangle$, due to temperature driven vibrations, see Table 3 . The refined profile agrees well with the observed results, see Fig. 3 (top), as shown by their difference, normalized by the statistical uncertainty in the observed neutron count, Stat. SD, as shown in Fig. 3 (bottom), which is randomly distributed around zero with reasonable deviations from it. The possibility of preferred orientation within the powder grains, the effect of the average powder grains size, and the possibility that the Ga atoms occupy the '4e' crystallographic site, were considered and 
found inconsistent with the observed results. In addition, the observed low-angle count is considerably high, (see inset in Fig. 3). As this count includes the 002 reflection, it was empirically taken into account within the analysis process. We speculate that this additional count may originate from a significant variance in $z_{\mathrm{Mo}}$ and $z_{\mathrm{Ga}}$, within each powder grain, from their mean respective values, which requires additional research.

The result from NPD Rietveld refinement, as summarized in Table 3, is in good agreement with the calculated structure as well as the XRD Rietveld analysis [13]. Apart from Table 3, the mean-square displacement $\left\langle\mathrm{u}^{2}\right\rangle$ of Mo, Ga, and C were determined to be $<0.01 \AA^{2}, \sim 0.03(1) \AA^{2}$, and $<0.01 \AA^{2}$, respectively. Moreover, the NPD analysis shows a C occupancy deviation $|x|<$ 0.03 , i.e. suggesting fully occupied octahedral sites, within the NPD precision, with C atoms between the Mo layers. This further validates our previously reported analysis and the present theoretical work, which were based on a fixed $100 \% \mathrm{C}$ occupancy on the octahedral sites.

Fig. 4 shows the electronic band structure and density of states (DOS) for $\mathrm{Mo}_{2} \mathrm{Ga}_{2} \mathrm{C}$. Nonbonding core states of $\mathrm{C} 2 \mathrm{~s}$ and $\mathrm{Ga} 2 \mathrm{~s}$ are located at -11.4 to $-12.9 \mathrm{eV}$ and -4 to $-10 \mathrm{eV}$, respectively. Between -4.3 and $-7.3 \mathrm{eV}$ the Mo $4 \mathrm{~d}$ and $\mathrm{C} 2 \mathrm{p}$ states form a hybridized bond. The peak around $-2.5 \mathrm{eV}$ shows partial hybridization of Mo $4 \mathrm{~d}$ and $\mathrm{Ga} 4 \mathrm{p}$ states. Between -2.5 $\mathrm{eV}$ and the Fermi level $\left(E_{f}\right)$ there are several peaks arising from both Mo $4 \mathrm{~d}$ and Ga $4 \mathrm{p}$ states, where none show any clear hybridization between each other. The peak located just below $E_{f}$ can mainly be attributed to Mo $4 \mathrm{~d}$ states. $E_{f}$ is located near a local minimum.

To obtain the elastic properties of $\mathrm{Mo}_{2} \mathrm{Ga}_{2} \mathrm{C}$, we used the method described by Fast et al. [28], where five different strains are applied to the hexagonal unit cell in order to obtain the five independent elastic constants $C_{11}, C_{12}, C_{13}, C_{33}$, and $C_{44}$. The strain values used to calculate the elastic constants were \pm 0.01 and \pm 0.02 . From the elastic constants $C_{i j}$ it is possible to estimate the Voigt bulk $\left(B_{V}\right)$ and shear $\left(G_{V}\right)$ moduli given by 


$$
B_{V}=\frac{2}{9}\left(C_{11}+C_{12}+2 C_{13}+C_{33} / 2\right)
$$

and

$$
G_{V}=115\left(2 C_{11}+C_{33}-C_{12}-2 C_{13}\right)+15\left(2 C_{44}+12\left(C_{11}-C_{12}\right)\right)
$$

In addition the Young's modulus $(E)$, Poisson's ratio $(v)$, and shear anisotropy factor $(A)$ is given by

$$
\begin{gathered}
E=\frac{9 B_{V} G_{V}}{3 B_{V}+G_{V}} \\
v=\frac{3 B_{V}-2 G_{V}}{2\left(3 B_{V}+G_{V}\right)} \\
A=\frac{4 C_{44}}{C_{11}+C_{33}-2 C_{13}}
\end{gathered}
$$

In Table 4, the calculated elastic properties for $\mathrm{Mo} 2 \mathrm{Ga} 2 \mathrm{C}$ are listed and compared to those of $\mathrm{Mo}_{2} \mathrm{GaC}$. It is evident that the additional $\mathrm{Ga}$ layer in $\mathrm{Mo}_{2} \mathrm{Ga}_{2} \mathrm{C}$ results in a significant reduction of most of the elastic constants, Poisson's ratio, and the anisotropy factor, $A$.

Fig. 5(a) is a STEM image acquired along the [210] zone axis of $\mathrm{Mo}_{2} \mathrm{Ga}_{2} \mathrm{C}$ from a thin film sample. Fig. 5(b) and (c) show Mo + Ga EDX maps (center) and superimposed STEM images with Mo + Ga EDX maps (bottom) from the same acquisition regions. In Fig. 5(a), the contrasts show a layered structure constructed by Mo layers (white) and Ga layers (light gray), which is further indicated by green 'Ga' labels. These results confirm those previously obtained [13]. What is additional here is the clear evidence for a stacking fault, where the double Ga layers of $\mathrm{Mo}_{2} \mathrm{Ga}_{2} \mathrm{C}$ merge into a single $\mathrm{Ga}$ layer characteristic of $\mathrm{Mo}_{2} \mathrm{GaC}$ denoted by vertical green line in Fig. 5(a). The transition region is imaged at a higher magnification in Fig. 5(c), from which it is obvious that two Ga layers on the right merge into one on the left. In other areas (Fig. 5(b)), 
single and double Ga layers are interleaved. In all cases, however, the Ga layers are separated by two Mo layers. The formation of such stacking faults most probably reflects local compositional Ga inhomogeneities. These micrographs suggest that one way to synthesize $\mathrm{Mo}_{2} \mathrm{Ga}_{2} \mathrm{C}$ is to anneal $\mathrm{Mo}_{2} \mathrm{GaC}$ in a Ga-rich environment.

A comparison between the XPS results for $\mathrm{Mo}_{2} \mathrm{Ga}_{2} \mathrm{C}$ and $\mathrm{Mo}_{2} \mathrm{GaC}$ is shown in Fig. 6, which presents the $\mathrm{O} 1 \mathrm{~s}, \mathrm{C}$ 1s, Mo 3d, and Ga 3p spectra for $\mathrm{Mo}_{2} \mathrm{GaC}$ (a) and $\mathrm{Mo}_{2} \mathrm{Ga}_{2} \mathrm{C}$ (b). The $\mathrm{O}$ 1s and $\mathrm{C}$ 1s spectra show that, despite the $\mathrm{Ar}^{+}$bombardment, the samples still exhibit oxide and graphite components as revealed through the $\mathrm{O} 1 \mathrm{~s}$ feature at 530.8 and $531.5 \mathrm{eV}$ and the $\mathrm{C} 1 \mathrm{~s}$ feature at 284.7 and $285.4 \mathrm{eV}$ for the $\mathrm{Mo}_{2} \mathrm{GaC}$ and $\mathrm{Mo}_{2} \mathrm{Ga}_{2} \mathrm{C}$ samples, respectively. More important, though, is the sharp carbide peaks at 283.3 and $283.7 \mathrm{eV}$ for $\mathrm{Mo}_{2} \mathrm{GaC}$ and $\mathrm{Mo}_{2} \mathrm{Ga}_{2} \mathrm{C}$, respectively. The Mo $3 d$ XPS spectra feature the primary spin-orbit components $3 d_{5 / 2}$ and $3 d_{3 / 2}$ at binding energies of 227.9 and $231.1 \mathrm{eV}$, respectively, for $\mathrm{Mo}_{2} \mathrm{GaC}$ and at binding energies of 228.1 and $231.3 \mathrm{eV}$, respectively, for $\mathrm{Mo}_{2} \mathrm{Ga}_{2} \mathrm{C}$. The $\mathrm{Ga} 3 \mathrm{p}_{3 / 2}$ and $3 \mathrm{p}_{1 / 2}$ components have the main features at binding energies of 104.0 and $107.1 \mathrm{eV}$, respectively, for $\mathrm{Mo}_{2} \mathrm{GaC}$ and binding energies of 104.1 and $107.3 \mathrm{eV}$, respectively, for $\mathrm{Mo}_{2} \mathrm{Ga}_{2} \mathrm{C}$.

To be able to interpret the XPS spectra presented in Fig. 6, it is necessary to compare them with the $3 p$ XPS component of a metallic Ga reference. The Ga 3p XPS spectra of the reference sample are presented in Fig. 7. Prior to the $\mathrm{Ar}^{+}$bombardment (Fig. 7(a)) the Ga reference sample has a native oxide, $\mathrm{Ga}_{2} \mathrm{O}_{3}$, surface layer, which is also indicated by the shoulder on the high binding energy side of the Ga $3 p_{1 / 2}$ peak. The corresponding Ga $3 p_{3 / 2}$ peak for the $\mathrm{Ga}_{2} \mathrm{O}_{3}$ phase is located between the primary spin-orbit components of the metallic Ga. After $\mathrm{Ar}^{+}$ bombardment of the Ga reference sample (Fig. 7(d)) the dominating features are the metallic Ga $3 p_{3 / 2}$ and $3 p_{1 / 2}$ peaks at 104.1 and $107.5 \mathrm{eV}$, respectively. Note that the peak locations for Ga in metallic Ga and in both MAX phases are almost identical. 
Included in Fig. 7 are also the corresponding spectra for the $\mathrm{Mo}_{2} \mathrm{GaC}$ and $\mathrm{Mo}_{2} \mathrm{Ga}_{2} \mathrm{C}$ MAXphases shown in Fig. 7(b) and (c), respectively. The comparison shows that the Ga in the MAXphases is partly oxidized and that the $\mathrm{Mo}_{2} \mathrm{GaC}$ sample is significantly more oxidized as compared to the $\mathrm{Mo}_{2} \mathrm{Ga}_{2} \mathrm{C}$ sample. Elemental quantification using the XPS spectra presented in Fig. 6 indicates that both samples consists of 20 at.\% of oxygen and with a O:Ga ratio of 1.4 and 0.32 for the $\mathrm{Mo}_{2} \mathrm{GaC}$ and $\mathrm{Mo}_{2} \mathrm{Ga}_{2} \mathrm{C}$ samples, respectively. However, the oxidation process is limited to the near surface region, which is probed by XPS, while the rest of the material is intact as evidenced by the only 0.34 at.\% O determined through using ERDA [13]. Since the samples are extensively exposed to the atmosphere, it is not unreasonable to assume that oxygen penetrates into the near surface region along grain boundaries and possibly further into the Galayers. The more oxidized Ga single-layer will have a different work function compared to the less oxidized Ga double-layer, which will cause an upward band bending and thus a depletion of electrons from the non-oxidized components in the sample [29]. This charge transfer is observed in Fig. 6, as all $\mathrm{Mo}_{2} \mathrm{GaC}$ spectra are shifted toward lower binding energies compared to those in the $\mathrm{Mo}_{2} \mathrm{Ga}_{2} \mathrm{C}$ phase.

This interpretation explains why the main features of the $\mathrm{O} 1 \mathrm{~s}, \mathrm{C} 1 \mathrm{~s}$, Mo 3d, and Ga 3p spectra for the $\mathrm{Mo}_{2} \mathrm{GaC}$ and the $\mathrm{Mo}_{2} \mathrm{Ga}_{2} \mathrm{C}$ in Fig. 6 do not line up. The broader appearance of the Mo $3 \mathrm{~d}_{5 / 2}$ for $\mathrm{Mo}_{2} \mathrm{GaC}$ and the shoulder on the low binding energy side of the main $3 \mathrm{~d}_{5 / 2}$ peak in $\mathrm{Mo}_{2} \mathrm{Ga}_{2} \mathrm{C}$ suggest that there is some double-layered $\mathrm{Ga}$ in $\mathrm{Mo}_{2} \mathrm{GaC}$ and some single-layered $\mathrm{Ga}$ in $\mathrm{Mo}_{2} \mathrm{Ga}_{2} \mathrm{C}$, consistent with the defects observed in Fig. 5. The additional intensity around $229.2 \mathrm{eV}$ in the Mo 3d spectrum for the $\mathrm{Mo}_{2} \mathrm{Ga}_{2} \mathrm{C}$ sample reveals the presence of $\mathrm{MoO}_{2}$ [30]. However, the most important observation is the similarity between the Mo $3 \mathrm{~d}$ and the $\mathrm{C} 1 \mathrm{~s}$ peaks of $\mathrm{Mo}_{2} \mathrm{GaC}, \mathrm{Mo}_{2} \mathrm{Ga}_{2} \mathrm{C}$, and $\mathrm{Mo}_{2} \mathrm{C}$ [31], see Fig. 8, which implies that both $\mathrm{Mo}_{2} \mathrm{GaC}$ and $\mathrm{Mo}_{2} \mathrm{Ga}_{2} \mathrm{C}$ consist of $\mathrm{Mo}_{2} \mathrm{C}$-layers. In fact, the XPS study confirms that there are no structural differences in the $\mathrm{Mo}_{2} \mathrm{C}$-layers between $\mathrm{Mo}_{2} \mathrm{GaC}$ and $\mathrm{Mo}_{2} \mathrm{Ga}_{2} \mathrm{C}$. 


\section{Conclusions}

We have performed first principles calculations in combination with experimental work including NPD Rietveld refinement, HR-STEM, and XPS, to explore the structure and chemistry of $\mathrm{Mo}_{2} \mathrm{Ga}_{2} \mathrm{C}$. The theoretical, as well as the experimental, results support the existence of a stoichiometric phase with a Ga bilayer - stacked in a simple hexagonal arrangement - between a pair of twinned $\mathrm{Mo}_{2} \mathrm{C}$ layers. It follows that the only structural difference between $\mathrm{Mo}_{2} \mathrm{Ga}_{2} \mathrm{C}$ and the well-known $\mathrm{Mo}_{2} \mathrm{GaC}$ MAX phase is the insertion of an additional Ga layer. Based on their similar structures and the track record of MAX phase discoveries, it is quite reasonable to assume that $\mathrm{Mo}_{2} \mathrm{Ga}_{2} \mathrm{C}$ is the first phase in a distinct family of MAX-related phases.

\section{Acknowledgments}

We acknowledge support from the Swedish Research Council (Project Grants \#621-2011-4420, 642-2013-8020, and 621-2014-4890), the Swedish Foundation for Strategic Research through the Synergy Grant FUNCASE Functional Carbides for Advanced Surface Engineering (C.-C.L., J.R., P.E., M.W.B.), the Future Research Leaders 5 Program (P.E., J.L.), and the ERC Grant agreement [No. 258509] (J.R.). The Knut and Alice Wallenberg Foundation is acknowledged for a Wallenberg Academy Fellowship (J.R.) and for supporting the Electron Microscopy Laboratory at Linköping University operated by the Thin Film Physics Division. Calculations were performed utilizing supercomputer resources supplied by the Swedish National Infrastructure for Computing (SNIC) at the High Performance Computing Center North (HPC2N) and National Supercomputer Centre (NSC). 


\section{References}

[1] M. W. Barsoum, MAX Phases: Properties of Machinable Carbides and Nitrides, Wiley VCH GmbH \& Co., Weinheim, 2013.

[2] P. Eklund, M. Beckers, U. Jansson, H. Högberg and L. Hultman, The $\mathrm{M}_{n+1} \mathrm{AX} \mathrm{X}_{n}$ phases: Materials science and thin-film processing, Thin Solid Films 518 (2010) 1851.

[3] Z. M. Sun, Progress in research and development on MAX phases: A family of layered ternary compounds, Int. Mater. Rev. 56 (2011) 143.

[4] M. W. Barsoum, The $\mathrm{M}_{\mathrm{N}+1} \mathrm{AX}_{\mathrm{N}}$ Phases: A New Class of Solids; Thermodynamically Stable Nanolaminates, Prog. Solid St. Chem. 28 (2000) 201.

[5] B. Holm, R. Ahuja, S. Li and B. Johansson, Theory of the ternary layered system TiAl-N, J. Appl. Phys. 91 (2002) 9874.

[6] A. Grechnev, S. Li, R. Ahuja, O. Eriksson, U. Jansson and O. Wilhelmsson, Layered compound $\mathrm{Nb}_{3} \mathrm{SiC}_{2}$ predicted from first-principles theory, Appl. Phys. Lett. 85 (2004) 3071 .

[7] W. Luo, C. M. Fang and R. Ahuja, Nanolayered MAX Phaes from $a b$ initio Calculations, Int. J. Modern Phys. B 22 (2008) 4495.

[8] C. Li, J. Kuo, B. Wang, Y. Li and R. Wang, A new layer compound $\mathrm{Nb}_{4} \mathrm{SiC}_{3}$ predicted from first-principles theory, J. Phys. D: Appl. Phys. 42 (2009) 075404.

[9] V. J. Keast, S. Harris and D. K. Smith, Prediction of the stability of the $M_{n+1} A X_{n}$ phases from first principles, Phys. Rev. B 80 (2009) 214113.

[10] P. Eklund, M. Dahlqvist, O. Tengstrand, L. Hultman, J. Lu, N. Nedfors, U. Jansson and J. Rosen, Discovery of the Ternary Nanolaminated Compound $\mathrm{Nb}_{2} \mathrm{GeC}$ by a Systematic Theoretical-Experimental Approach, Phys. Rev. Lett. 109 (2012) 035502. 
[11] A. S. Ingason, A. Mockute, M. Dahlqvist, F. Magnus, S. Olafsson, U. B. Arnalds, B. Alling, I. A. Abrikosov, B. Hjörvarsson, P. O. Å. Persson and J. Rosen, Magnetic SelfOrganized Atomic Laminate from First Principles and Thin Film Synthesis, Phys. Rev. Lett. 110 (2013) 195592.

[12] A. S. Ingason, A. Petruhins, M. Dahlqvist, F. Magnus, A. Mockute, B. Alling, L. Hultman, I. A. Abrikosov, P. O. Å. Persson and J. Rosen, A Nanolaminated Magnetic Phase: $\mathrm{Mn}_{2} \mathrm{GaC}$, Mater. Res. Lett. 2 (2014) 89.

[13] C. Hu, C.-C. Lai, Q. Tao, J. Lu, J. Halim, L. Sun, J. Zhang, J. Yang, B. Anasori, J. Wang, Y. Sakka, L. Hultman, P. Eklund, J. Rosen and M. W. Barsoum, $\mathrm{Mo}_{2} \mathrm{Ga}_{2} \mathrm{C}$ : a new ternary nanolaminated carbide, Chem. Commun. 51 (2015) 6560.

[14] R. Meshkian, A. S. Ingason, M. Dahlqvist, A. Petruhins, U. B. Arnalds, F. Magnus, J. Lu and J. Rosen, Theoretical stability, thin film synthesis and transport properties of the $\mathrm{Mo}_{n+1} \mathrm{GaC}_{n}$ MAX phase, Phys. Status Solidi RRL 9 (2015) 197.

[15] P. E. Blöchl, Projector augmented-wave method, Phys. Rev. B 50 (1994) 17953.

[16] G. Kresse and J. Hafner, Ab initio molecular dynamics for open-shell transition metals , Phys. Rev. B 48 (1993) 13115.

[17] G. Kresse and D. Joubert, From ultrasoft pseudopotentials to the projector augmentedwave method, Phys. Rev. B 59 (1999) 1758.

[18] G. Kresse and J. Hafner, Ab initio molecular-dynamics simulation of the liquid-metalamorphous-semiconductor transition in germanium, Phys. Rev. B 49 (1994) 14251.

[19] J. P. Perdew, K. Burke and M. Ernzerhof, Generalized Gradient Approximation Made Simple, Phys. Rev. Lett. 77 (1996) 3865.

[20] H. J. Monkhorst and J. D. Pack, Special points for Brillouin-zone integrations, Phys. Rev. B 13 (1976) 5188. 
[21] A. Petruhins, A. S. Ingason, M. Dahlqvist, A. Mockute, M. Junaid, J. Birch, J. Lu, L. Hultman, P. O. A. Persson and J. Rosen, Phase stability of $\mathrm{Cr}_{n+1} \mathrm{GaC}_{n}$ MAX phases from first principles and $\mathrm{Cr}_{2} \mathrm{GaC}$ thin-film synthesis using magnetron sputtering from elemental targets, Phys. Status Solidi RRL 7 (2013) 971.

[22] O. Rivin, E. N. Caspi, H. Ettedgui, H. Shaked and A. Goukassov, Magnetic structure determination of $\mathrm{TbCo}_{2} \mathrm{Ni}_{3}$ using polarized and nonpolarized neutron powder diffraction, Phys. Rev. B 88 (2013) 054430.

[23] J. R. Carvajal, Recent advances in magnetic structure determination neutron powder diffraction, Physica B 192 (1993) 55.

[24] M. Dahlqvist, B. Alling, I. A. Abrikosov and J. Rosen, Phase stability of Ti 2 AlC upon oxygen incorporation: A first-principles investigation, Phys. Rev. B 81 (2010) 024111.

[25] M. Dahlqvist, B. Alling and J. Rosen, Stability trends of MAX phases from first principles, Phys. Rev. B 81 (2010) 220102.

[26] A. Mockute, M. Dahlqvist, J. Emmerlich, L. Hultman, J. M. Schneider, P. O. Å. Persson and J. Rosen, Synthesis and $a b$ initio calculations of nanolaminated $(\mathrm{Cr}, \mathrm{Mn})_{2} \mathrm{AlC}$ compounds, Phys. Rev. B 87 (2013) 094113.

[27] A. Mockute, P. O. Å. Persson, F. Magnus, A. S. Ingason, S. Olafsson, L. Hultman and J. Rosen, Synthesis and characterization of arc deposited magnetic $(\mathrm{Cr}, \mathrm{Mn})_{2} \mathrm{AlC} \mathrm{MAX}$ phase films, Phys. Status Solidi RRL. 8 (2014) 420.

[28] L. Fast, J. M. Wills, B. Johansson and O. Eriksson, Elastic constants of hexagonal transition metals: Theory, Phys. Rev. B 51 (1995) 17431.

[29] Z. Zhang and J. T. Yates, Jr., Band Bending in Semiconductors: Chemical and Physical Consequences at Surfaces and Interfaces, Chem. Rev. 112 (2012) 5520. 
[30] T. Schroeder, J. Zegenhagen, N. Magg, B. Immaraporn and H.-J. Freund, Formation of a faceted $\mathrm{MoO}_{2}$ epilayer on Mo(1 112 ) studied by XPS, UPS and STM, Surf. Sci. 552 (2004) 85 .

[31] C. A. Wolden, A. Pickerell, T. Gawai, S. Parks, J. Hensley and J. D. Way, Synthesis of $\beta-\mathrm{Mo}_{2} \mathrm{C}$ Thin Films, ACS Appl. Mater. Interfaces 3 (2011) 517. 
Table 1. Calculated unit cell volume, lattice parameters, and total energies, per formula unit, for competing phases considered in the ternary Mo-Ga-C system. The values for $\mathrm{Mo}_{2} \mathrm{Ga}_{2} \mathrm{C}$ phases are listed in Table 2.

\begin{tabular}{|c|c|c|c|c|c|c|c|c|}
\hline Phase & $\begin{array}{l}\text { Prototype } \\
\text { structure }\end{array}$ & $\begin{array}{l}\text { Pearson } \\
\text { symbol }\end{array}$ & Space group & $\begin{array}{c}V_{0} \\
\left(\AA^{3 / u c}\right)\end{array}$ & $\begin{array}{c}\mathrm{a} \\
(\AA)\end{array}$ & $\begin{array}{c}b \\
(\AA)\end{array}$ & $\begin{array}{c}c \\
(\AA)\end{array}$ & $E_{0}(\mathrm{eV} / \mathrm{fu})$ \\
\hline Mo & $\mathrm{W}$ & $\mathrm{cI} 2$ & $\operatorname{Im} \overline{3} m(229)$ & 15.92 & 3.169 & & & -10.850 \\
\hline Mo & $\mathrm{Cu}$ & $\mathrm{cF} 4$ & $F m \overline{3} m(225)$ & 16.15 & 4.012 & & & -10.431 \\
\hline Mo & $\mathrm{Mg}$ & $\mathrm{hP} 2$ & $P 6_{3} / m m c(194)$ & 32.57 & 2.774 & & 4.887 & -10.414 \\
\hline $\mathrm{Ga}$ & $\alpha-G a$ & oC8 & Cmca (64) & 162.77 & 4.590 & 7.753 & 4.575 & -3.030 \\
\hline $\mathrm{Ga}$ & $\mathrm{Ga}$ & oC4 & $\mathrm{Cmcm}$ (63) & 38.43 & 2.795 & 8.114 & 3.380 & -3.012 \\
\hline $\mathrm{Ga}$ & $\mathrm{Ga}$ & $\mathrm{mC} 4$ & $\mathrm{C} 2 / \mathrm{c}(15)$ & 38.38 & 2.818 & 8.167 & 3.330 & -3.012 \\
\hline $\mathrm{C}$ & $\mathrm{C}$ (graphite) & hP4 & $P 6_{3} / m m c$ & 38.14 & 2.464 & & 7.250 & -9.225 \\
\hline $\mathrm{MoC}$ & TiP & hP8 & $P 6_{3} / m m c$ & 84.84 & 3.016 & & 10.768 & -19.821 \\
\hline $\mathrm{MoC}$ & $\mathrm{NaCl}$ & $\mathrm{cF} 8$ & $F m \overline{3} m(225)$ & 21.06 & 4.383 & & & -19.640 \\
\hline $\mathrm{MoC}$ & $\eta-\mathrm{MoC}$ & hp12 & $P 6_{3} / m m c$ & 126.16 & 3.074 & & 15.401 & -19.747 \\
\hline $\mathrm{MoC}$ & WC & hp2 & $P \overline{6} m 2$ (187) & 21.00 & 2.928 & & 2.829 & -20.241 \\
\hline $\mathrm{Mo}_{3} \mathrm{C}_{2}$ & $\mathrm{Cr}_{3} \mathrm{C}_{2}$ & oP20 & Pnma (62) & 228.19 & 6.064 & 2.974 & 12.654 & -50.938 \\
\hline $\mathrm{Mo}_{2} \mathrm{C}$ & $\beta^{\prime \prime}-\mathrm{Mo}_{2} \mathrm{C}$ & $\mathrm{hP} 3$ & $P \overline{3} m 1$ (164) & 38.06 & 3.068 & & 4.669 & -31.064 \\
\hline $\mathrm{Mo}_{3} \mathrm{C}$ & $\mathrm{Fe}_{3} \mathrm{C}$ & oP16 & Pnma (62) & 215.87 & 5.540 & 7.559 & 5.159 & -40.423 \\
\hline $\mathrm{Mo}_{6} \mathrm{Ga}_{31}$ & $\mathrm{Mo}_{6} \mathrm{Ga}_{31}$ & $\mathrm{mP} 148$ & $P 2_{1} / c(14)$ & 2647.42 & & & & -163.927 \\
\hline $\mathrm{Mo}_{8} \mathrm{Ga}_{41}$ & $\mathrm{~V}_{8} \mathrm{Ga}_{41}$ & hR147 & $P \overline{3}(148)$ & 2625.14 & & & & -217.436 \\
\hline $\mathrm{MoGa}_{4}$ & $\mathrm{CrGa}_{4}$ & cI10 & $\operatorname{Im} \overline{3} m(229)$ & 102.47 & 5.106 & & & -23.818 \\
\hline $\mathrm{MoGa}_{3}$ & $\mathrm{TiAl}_{3}$ & $\mathrm{tI} 8$ & I4/mmm (139) & 72.10 & 5.189 & & 5.428 & -18.485 \\
\hline $\mathrm{MoGa}_{2}$ & $\mathrm{CdI}_{2}$ & $\mathrm{hP} 3$ & $P \overline{3} m 1$ (164) & 48.84 & 2.904 & & 6.689 & -16.658 \\
\hline $\mathrm{Mo}_{2} \mathrm{Ga}_{3}$ & $\mathrm{Ti}_{2} \mathrm{Ga}_{3}$ & $\mathrm{tP} 10$ & $P 4 / m(83)$ & 155.67 & 6.515 & & 3.667 & -30.851 \\
\hline MoGa & $\mathrm{FeSi}$ & cP8 & $P 2_{1} 3(198)$ & 126.05 & 5.014 & & & -13.760 \\
\hline $\mathrm{Mo}_{5} \mathrm{Ga}_{4}$ & $\mathrm{Ti}_{5} \mathrm{Ga}_{4}$ & hP18 & $\mathrm{PG}_{3} / \mathrm{mcm}$ & 276.95 & 7.817 & & 5.234 & -66.314 \\
\hline $\mathrm{Mo}_{3} \mathrm{Ga}_{2}$ & $\mathrm{U}_{3} \mathrm{Si}_{2}$ & tP10 & $P 4 / m b m(127)$ & 154.78 & 6.784 & & 3.363 & -38.294 \\
\hline $\mathrm{Mo}_{5} \mathrm{Ga}_{3}$ & $\mathrm{Cr}_{5} \mathrm{As}_{3}$ & oP32 & Pnma (62) & 510.53 & 9.839 & 7.807 & 6.639 & -62.659 \\
\hline $\mathrm{Mo}_{2} \mathrm{Ga}$ & $\mathrm{Cu}_{2} \mathrm{Sb}$ & tP6 & $P 4 / m m m(129)$ & 95.73 & 3.682 & & 7.062 & -24.438 \\
\hline $\mathrm{Mo}_{2} \mathrm{Ga}$ & $\mathrm{Fe}_{2} \mathrm{P}$ & hP9 & $P \overline{6} 2 m(189)$ & 140.12 & 7.192 & & 3.127 & -24.527 \\
\hline $\mathrm{Mo}_{5} \mathrm{Ga}_{2}$ & $\mathrm{Mn}_{5} \mathrm{Ge}_{2}$ & $\mathrm{hP} 42$ & $P 3 c 1(158)$ & 670.89 & & & & -59.508 \\
\hline $\mathrm{Mo}_{3} \mathrm{Ga}$ & $\mathrm{Cr}_{3} \mathrm{Si}$ & $\mathrm{cP} 8$ & $P m \overline{3} n(223)$ & 123.39 & 4.979 & & & -36.200 \\
\hline $\mathrm{Mo}_{3} \mathrm{GaC}$ & $\mathrm{CaTiO}_{3}$ & cP5 & $P m \overline{3} m(221)$ & 71.57 & 4.152 & & & -44.274 \\
\hline $\mathrm{Mo}_{2} \mathrm{GaC}$ & $\mathrm{Cr}_{2} \mathrm{AlC}$ & hP8 & $P 6_{3} / m m c$ & 108.20 & 3.068 & & 13.272 & -34.413 \\
\hline $\mathrm{Mo}_{3} \mathrm{GaC}_{2}$ & $\mathrm{Ti}_{3} \mathrm{SiC}_{2}$ & hP12 & $P 6_{3} / m m c(194)$ & 151.38 & 3.086 & & 18.358 & -54.040 \\
\hline $\mathrm{Mo}_{4} \mathrm{GaC}_{3}$ & $\mathrm{Ti}_{4} \mathrm{AlN}_{3}$ & hP16 & $P 6_{3} / m m c$ & 196.55 & 3.133 & & 23.116 & -73.789 \\
\hline
\end{tabular}


Table 2 Structural and stability related information for the three crystal structures with $\mathrm{Mo}_{2} \mathrm{Ga}_{2} \mathrm{C}$ composition presented in Fig. 1 . The negative values for $\Delta H_{c p}$ indicate stability relative to the set of most competing phases.

\begin{tabular}{|c|c|c|c|c|c|c|}
\hline & $\begin{array}{c}V_{0} \\
\left(\AA^{3} / \mathrm{uc}\right)\end{array}$ & $a(\AA)$ & $c(\AA)$ & $E_{0}(\mathrm{eV} / \mathrm{uc})$ & $\begin{array}{c}\Delta E_{\text {single }} \\
\text { (meV/atom) }\end{array}$ & $\begin{array}{c}\Delta H_{c p} \\
\text { (meV/atom) }\end{array}$ \\
\hline C between Mo-layers (Figure 1(a)) ${ }^{\dagger}$ & 147.59 & 3.064 & 18.153 & -75.384 & -142 & -9 \\
\hline $\mathrm{C}$ between Ga-layers (Figure 1(b)) & 143.41 & 3.068 & 17.596 & -67.438 & +653 & +786 \\
\hline $\mathrm{C}$ between Mo-layers and zig-zag stacking of Ga (Figure $1(\mathrm{c}))^{\ddagger}$ & 146.47 & 3.091 & 17.705 & -74.057 & -9 & +124 \\
\hline
\end{tabular}

${ }^{\dagger}$ Identified set of most competing phases at $\mathrm{Mo}_{2} \mathrm{Ga}_{2} \mathrm{C}$ composition are $\mathrm{Mo}_{3} \mathrm{Ga}, \mathrm{MoC}$, and $\mathrm{MoGa}_{4}$.

${ }^{\ddagger}$ Note that the space group considered for the zig-zag stacked $\mathrm{Mo}_{2} \mathrm{Ga}_{2} \mathrm{C}$ is $P \overline{3} m 1$ (164).

Table $3 a$ and $c$ lattice parameters and structural models of $\mathrm{Mo}_{2} \mathrm{Ga}_{2} \mathrm{C}$ obtained from the calculation (only the most stable structure, Fig. 1(a)) and from Rietveld analysis of XRD and NPD patterns.

\begin{tabular}{|c|c|c|c|c|c|c|c|c|c|c|c|c|}
\hline & $\begin{array}{l}\text { Calculation } \\
\text { (Fig. 1(a)) }\end{array}$ & & & & $\begin{array}{l}\text { XRD } \\
\text { (from [13]) }\end{array}$ & & & & $\mathrm{NPD}^{\dagger}$ & & & \\
\hline$a(\AA)$ & 3.06396 & & & & $3.03396(4)$ & & & & $3.03(1)$ & & & \\
\hline$c(\AA)$ & 18.1532 & & & & $18.0814(3)$ & & & & 18.1(1) & & & \\
\hline \multirow[t]{2}{*}{$\begin{array}{l}\text { Space } \\
\text { Group }\end{array}$} & $\mathrm{P}_{3} / \mathrm{mmc}$ & & & & $P 6_{3} / m m c$ & & & & $\mathrm{~Pb}_{3} / \mathrm{mmc}$ & & & \\
\hline & $\begin{array}{l}\text { Wyckoff } \\
\text { Notation }\end{array}$ & $\mathrm{x}$ & $\mathrm{y}$ & $\mathrm{z}$ & $\begin{array}{l}\text { Wyckoff } \\
\text { Notation }\end{array}$ & $\mathrm{x}$ & $\mathrm{y}$ & $\mathrm{z}$ & $\begin{array}{l}\text { Wyckoff } \\
\text { Notation }\end{array}$ & $\mathrm{x}$ & $\mathrm{y}$ & $\mathrm{z}$ \\
\hline Mo & $4 \mathrm{f}$ & $1 / 3$ & $2 / 3$ & 0.06489 & $4 \mathrm{f}$ & $1 / 3$ & $2 / 3$ & $0.06571(11)$ & $4 \mathrm{f}$ & $1 / 3$ & $2 / 3$ & $0.065(8)$ \\
\hline $\mathrm{Ga}$ & $4 \mathrm{f}$ & $1 / 3$ & $2 / 3$ & 0.68132 & $4 \mathrm{f}$ & $1 / 3$ & $2 / 3$ & $0.68247(13)$ & $4 \mathrm{f}$ & $1 / 3$ & $2 / 3$ & $0.69(1)$ \\
\hline $\mathrm{C}$ & $2 a$ & 0 & 0 & 0 & $2 a$ & 0 & 0 & 0 & $2 a$ & 0 & 0 & 0 \\
\hline
\end{tabular}


Table 4 Calculated elastic constants $C_{i j}$, bulk moduli $B_{V}$, shear moduli $G_{V}$, Young's moduli $E$, Poisson's ratio $v$, and the anisotropy factor $A$ for $\mathrm{Mo}_{2} \mathrm{Ga}_{2} \mathrm{C}$ (Fig. 1(a)) and $\mathrm{Mo}_{2} \mathrm{GaC}_{\text {. }}$

\begin{tabular}{lcccccccccc}
\hline \hline Phase & $\begin{array}{c}C_{11} \\
(\mathrm{GPa})\end{array}$ & $\begin{array}{c}C_{12} \\
(\mathrm{GPa})\end{array}$ & $\begin{array}{c}C_{13} \\
(\mathrm{GPa})\end{array}$ & $\begin{array}{c}C_{33} \\
(\mathrm{GPa})\end{array}$ & $\begin{array}{c}C_{44} \\
(\mathrm{GPa})\end{array}$ & $\begin{array}{c}B_{V} \\
(\mathrm{GPa})\end{array}$ & $\begin{array}{c}G_{V} \\
(\mathrm{GPa})\end{array}$ & $E(\mathrm{GPa})$ & $v$ & $A$ \\
\hline $\mathrm{Mo}_{2} \mathrm{Ga}_{2} \mathrm{C}$ & 244 & 62 & 108 & 341 & 78 & 154 & 86 & 218 & 0.26 \\
$\mathrm{Mo}_{2} \mathrm{GaC}$ & 294 & 96 & 161 & 289 & 126 & 190 & 101 & 257 & 0.85 & 1.93 \\
\hline \hline
\end{tabular}




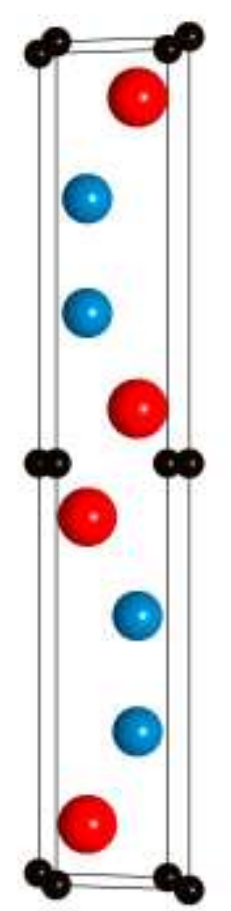

(a)

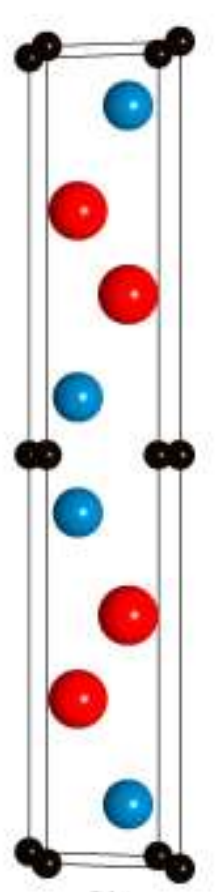

(b)

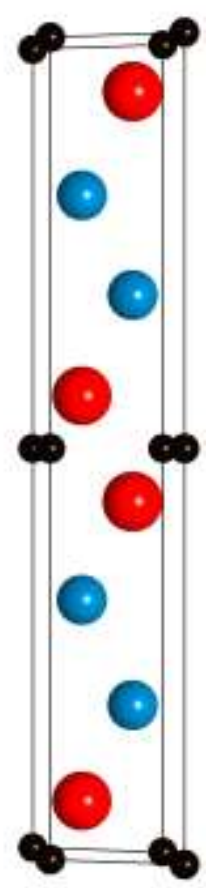

(c)

Fig. 1. Crystal structures of $\mathrm{Mo}_{2} \mathrm{Ga}_{2} \mathrm{C}$ composition with (a) $\mathrm{C}$ atoms between the Mo-layers, (b) $\mathrm{C}$ atoms between Ga-layers, and (c) $\mathrm{C}$ atoms between Mo-layer but a zig-zag stacking of the $\mathrm{Ga}$ atoms, where the Mo atoms are in red, $\mathrm{Ga}$ in blue and $\mathrm{C}$ in black. All illustrations are scaled accordingly to their actual structure sizes. 

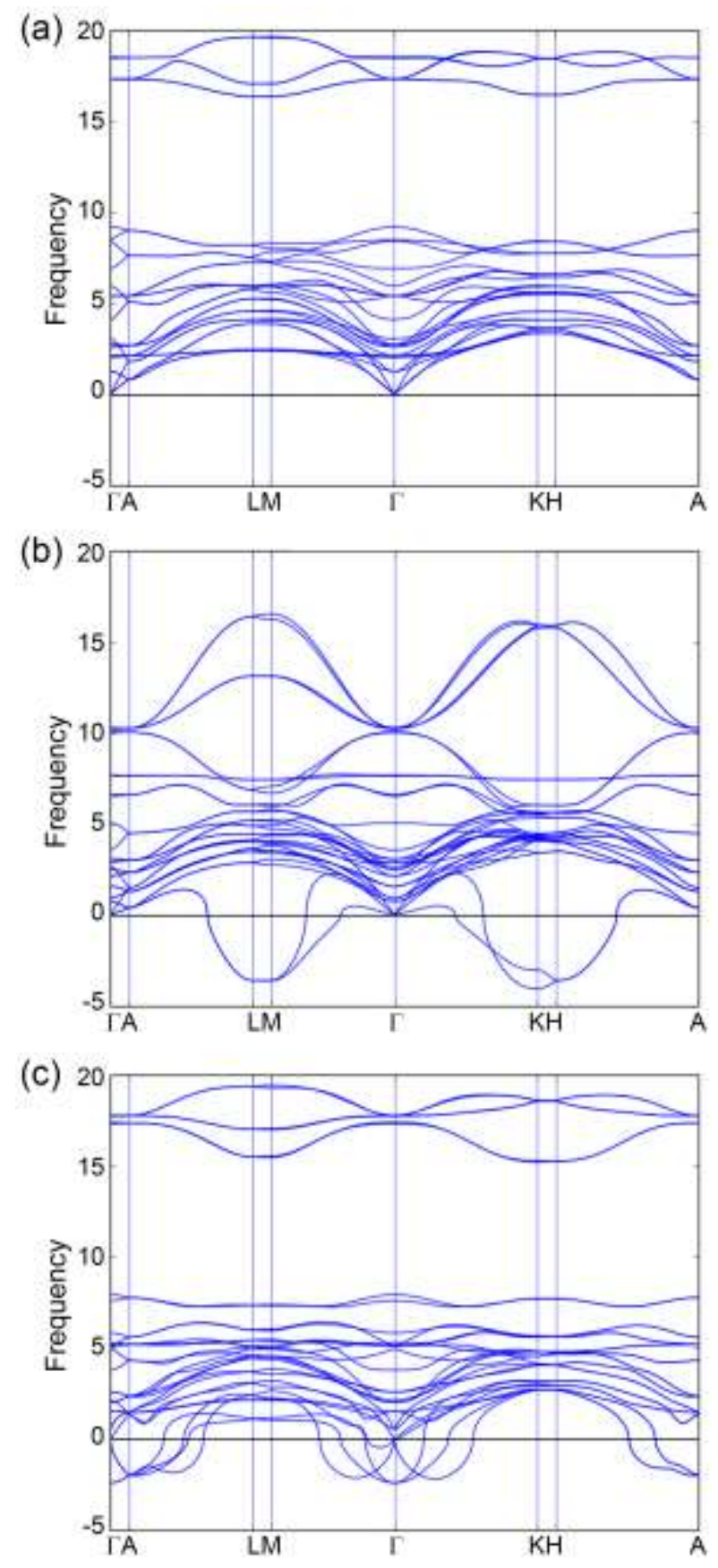

Fig. 2. Dynamical stability of $\mathrm{Mo}_{2} \mathrm{Ga}_{2} \mathrm{C}$ composition with (a) $\mathrm{C}$ atoms between the Mo-layers, (b) $\mathrm{C}$ atoms between Ga-layers, and (c) $\mathrm{C}$ atoms between Mo-layer but a zig-zag stacking of the Ga atoms. 


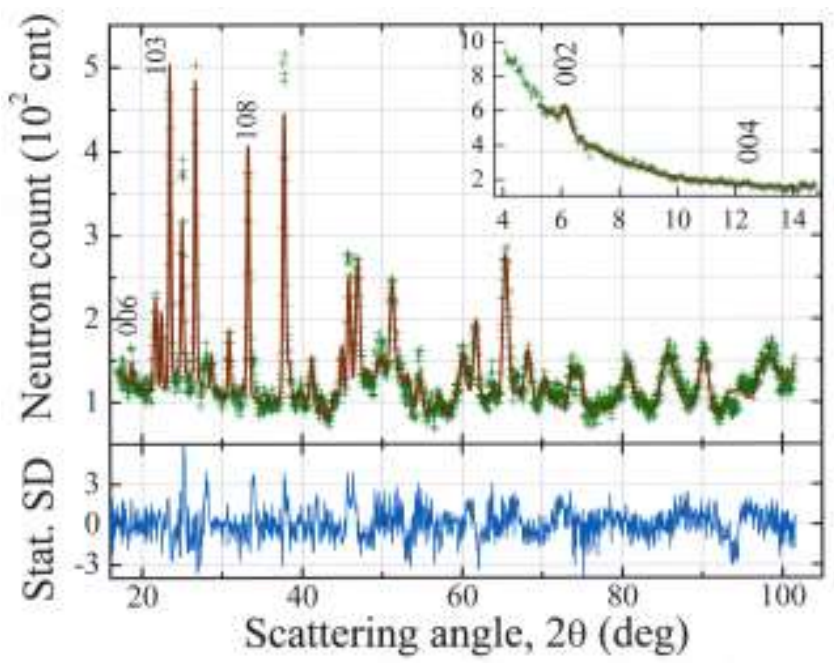

Fig. 3. $\mathrm{NPD}$ of $\mathrm{Mo}_{2} \mathrm{Ga}_{2} \mathrm{C}$, observed at room temperature (crosses) as a function of scattering angle, $2 \theta$. The Rietveld refined NPD profile (top) is shown to fit the observed count, determined by the difference between the observed and refined profiles (bottom), normalized by the statistical uncertainty in the observed count (see text). The inset at the top-right corner presents the low-angle count. Selected reflections are denoted using their Miller indices.

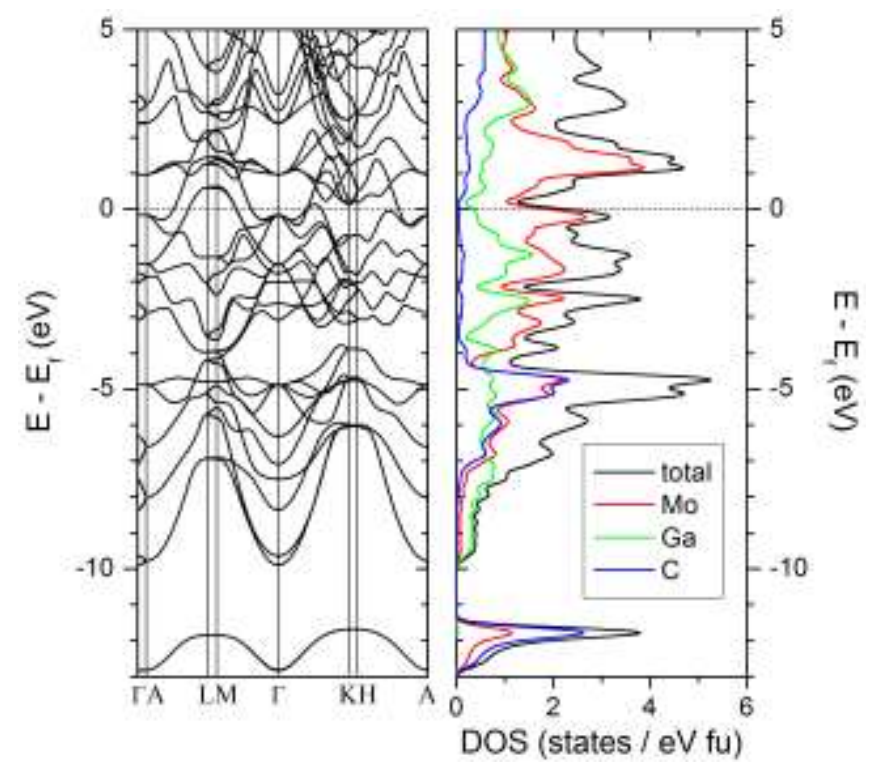

Fig. 4. Calculated electronic band structure (left) and density of states (right) for $\mathrm{Mo}_{2} \mathrm{Ga}_{2} \mathrm{C}$ for the structure shown in Fig. 1(a). The Fermi level is indicated by the horizontal dashed line. 

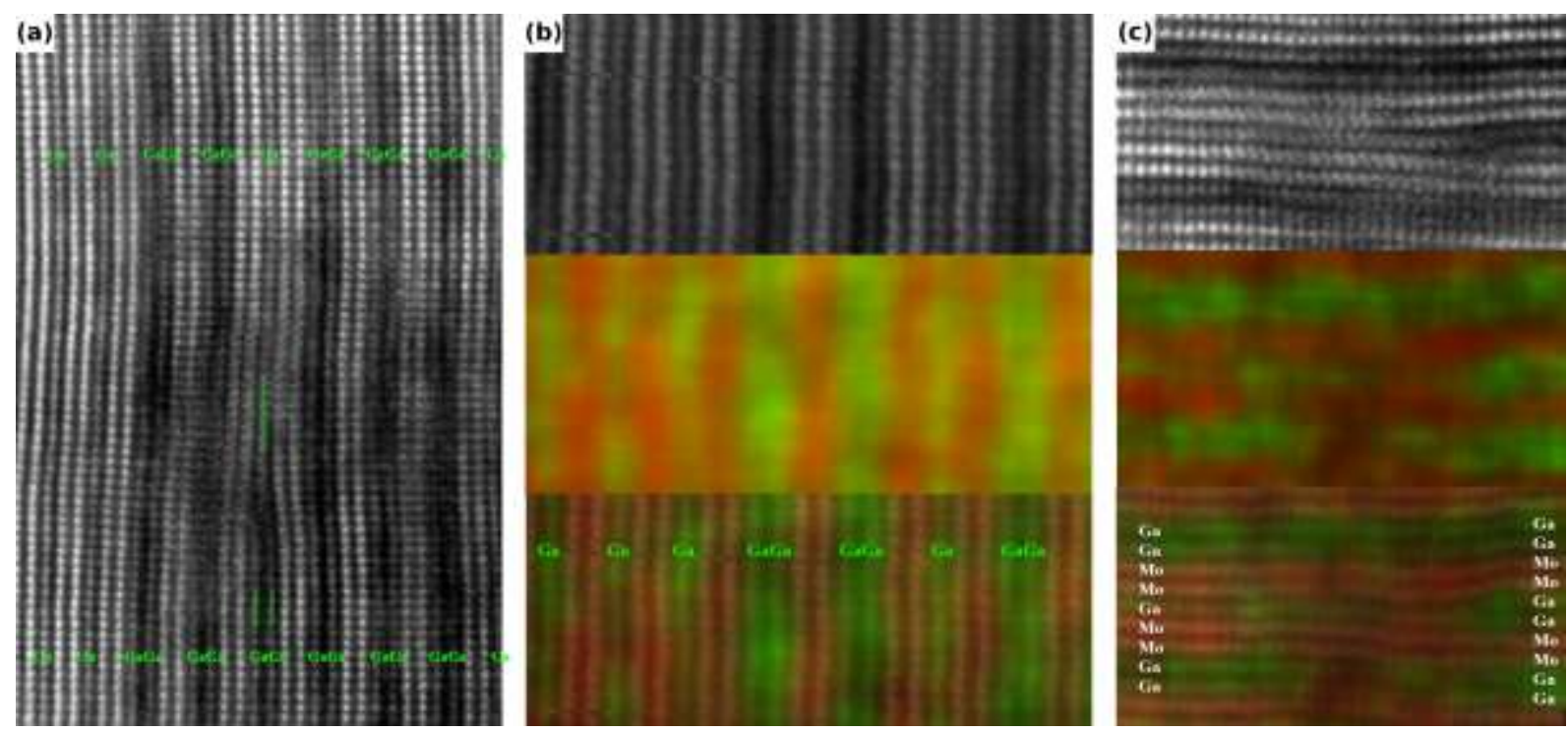

Fig. 5. (a) STEM image of $\mathrm{Mo}_{2} \mathrm{Ga}_{2} \mathrm{C}$ phase acquired along its [210] zone axis, where the $\mathrm{Ga}$ layers are highlighted with green 'Ga' labels and lines. (b and c) STEM images (top), Mo + Ga EDX mappings (center), and superimposed STEM images and Mo + Ga EDX mappings (bottom) of $\mathrm{Mo}_{2} \mathrm{Ga}_{2} \mathrm{C}$ phase acquired along the [210] zone axis. 

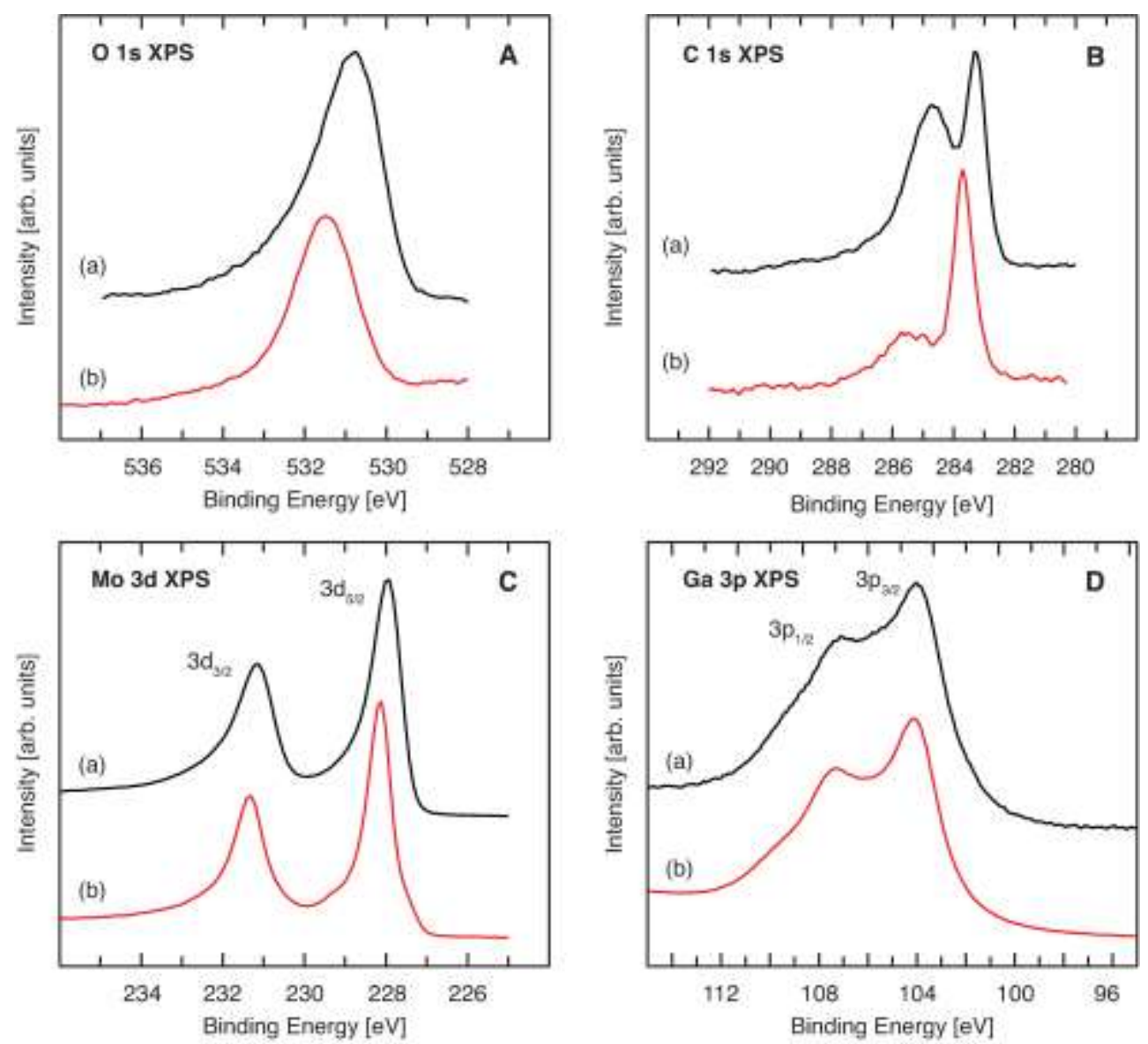

Fig. 6. XPS spectra for (a) $\mathrm{Mo}_{2} \mathrm{GaC}$ and (b) $\mathrm{Mo}_{2} \mathrm{Ga}_{2} \mathrm{C}$. Panels (A)-(D) show the $\mathrm{O} 1 \mathrm{~s}, \mathrm{C} 1 \mathrm{~s}$, Mo 3d, and Ga 3p regions, respectively. 


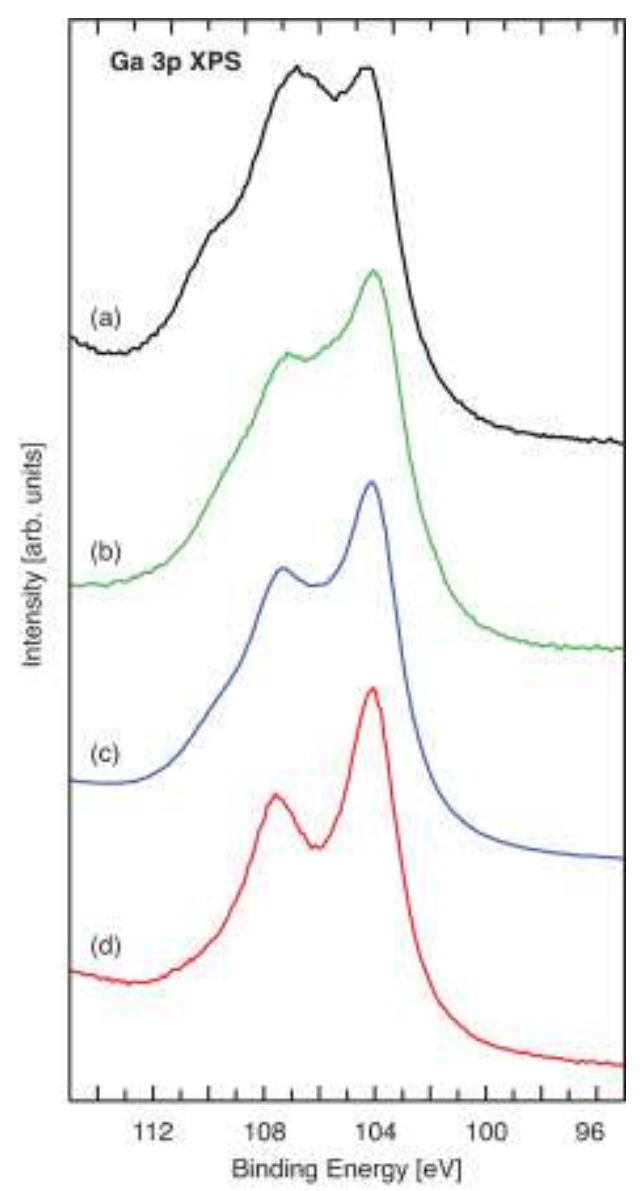

Fig. 7. Ga 3p XPS spectra for (a) metallic $\mathrm{Ga}$ with native $\mathrm{Ga}_{2} \mathrm{O}_{3}$ surface layer, (b) $\mathrm{Mo}_{2} \mathrm{GaC}$, (c) $\mathrm{Mo}_{2} \mathrm{Ga}_{2} \mathrm{C}$, and (d) metallic $\mathrm{Ga}$ after $500 \mathrm{eV} \mathrm{Ar}{ }^{+}$bombardment. 

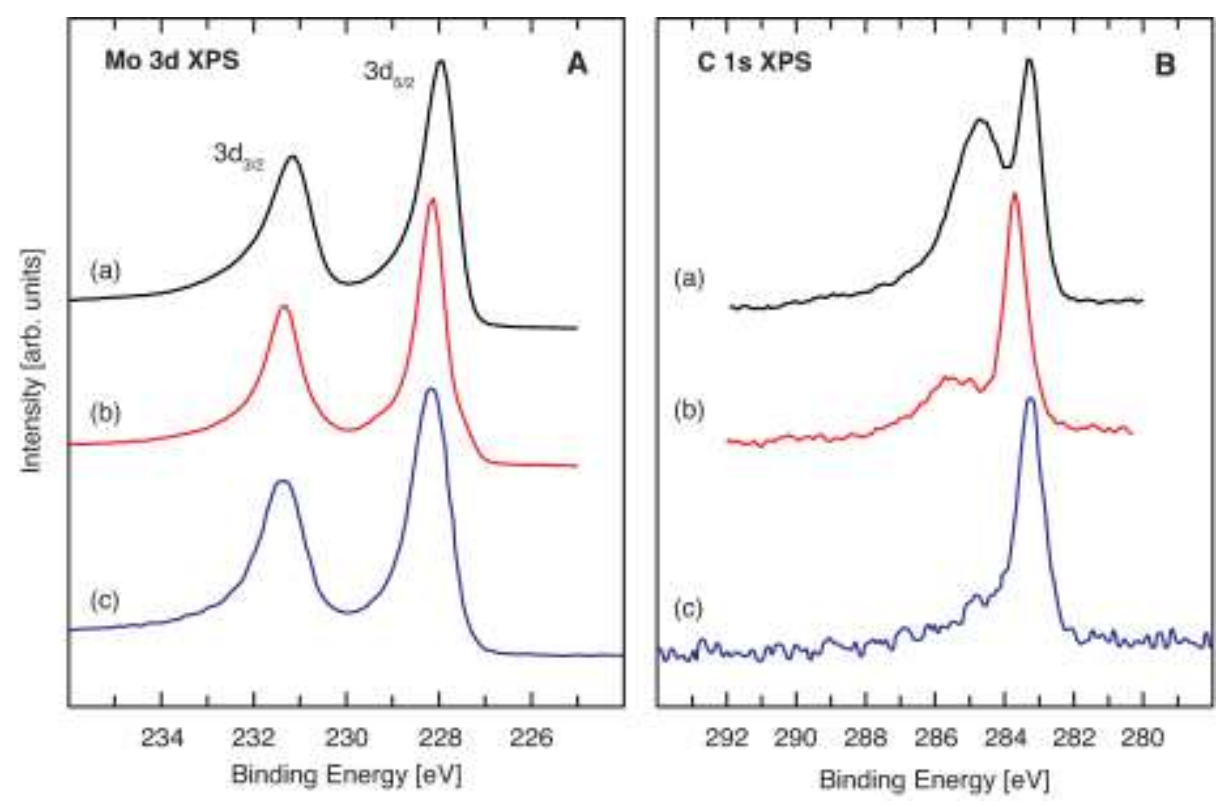

Fig. 8. XPS spectra for (a) $\mathrm{Mo}_{2} \mathrm{GaC}$, (b) $\mathrm{Mo}_{2} \mathrm{Ga}_{2} \mathrm{C}$, and (c) $\beta-\mathrm{Mo}_{2} \mathrm{C}$ obtained from Ref. [31]. Panels (A) and (B) show the Mo 3d and C 1s regions, respectively. 